BNL 69145

\title{
Improving Control Room Design and Operations Based on Human Factors Analyses Or How Much Human Factors Upgrade is Enough?
}

James C. Higgins, John M. O'Hara, and Pilar Almeida

May 9, 2002

Energy Sciences \& Technology Department

Brookhaven National Laboratory

Operated by

Brookhaven Science Associates

Upton, NY 11973

Under Contract with the United States Department of Energy

Contract Number DE-AC02-98CH10886 


\section{DISCLAIMER}

This report was prepared as an account of work sponsored by an agency of the United States Government. Neither the United States Government nor any agency thereof, nor any of their employees, nor any of their contractors, subcontractors or their employees, makes any warranty, express or implied, or assumes any legal liability or responsibility for the accuracy, completeness, or any third party's use or the results of such use of any information, apparatus, product, or process disclosed, or represents that its use would not infringe privately owned rights. Reference herein to any specific commercial product, process, or service by trade name, trademark, manufacturer, or otherwise, does not necessary constitute or imply its endorsement, recommendation, or favoring by the United States Government or any agency thereof or its contractors or subcontractors. The views and opinions of authors expresses herein do not necessarily state to reflect those of the United States Government or any agency thereof. 


\title{
Improving Control Room Design and Operations Based on Human Factors Analyses
}

\section{or \\ How Much Human Factors Upgrade is Enough?}

\author{
James C. Higgins, Senior Member, IEEE, John M. O'Hara, and Pilar Almeida
}

\begin{abstract}
The José Cabrera Nuclear Power Plant is a one loop Westinghouse pressurized water reactor. In the control room, the displays and controls used by operators for the emergency operating procedures are distributed on front and back panels. This configuration contributed to risk in the Probabilistic Safety Assessment where important operator actions are required. This study was undertaken to evaluate the impact of the design on crew performance and plant safety and to develop design improvements. Five potential effects were identified. Then NUREG-0711 [1], programmatic, human factors, analyses were conducted to systematically evaluate the CR-layout to determine if there was evidence of the potential effects. These analyses included operating experience review, PSA review, task analyses, and walkthrough simulations. Based on the results of these analyses, a variety of control room modifications were identified. From the alternatives, a selection was made that provided a reasonable balance between performance, risk and economics, and modifications were made to the plant.
\end{abstract}

Index Terms--control systems, human factors, nuclear power generation control, nuclear power generation safety, risk analysis, safety, simulation.

\section{NOMENCLATURE}

CNJC Jose Cabrera nuclear power plant

CSN Consejo de Seguridad Nuclear

CRDR control room design review

EOP emergency operating procedure

HED human engineering discrepancy

HSI human system interface

LOCA loss of coolant acident

LOOP loss of offsite power

MCR main control room

This work was performed under the auspices of U.S. Department of Energy as supported by Union Fenosa Generacion.

J. C. Higgins is with Brookhaven National Laboratory, Upton, NY 11973 USA (e-mail: higgins@bnl.gov).

J. M. O'Hara is with Brookhaven National Laboratory, Upton, NY 11973 USA (e-mail: ohara@bnl.gov).

P. Almeida is with SOLUZIONA Ingeniería of Madrid, Spain (e-mail: palmeida@soluziona.com)
NPP nuclear power plant

PSA probabilistic safety assessment

PWR pressurized water reactor

$\mathrm{RO}$ reactor operator

SGTR steam generator tube rupture

SI safety injection

SPDS safety parameter display system

TO turbine operator

UF Union Fenosa

\section{INTRODUCTION}

$T$ he José Cabrera Nuclear Power Plant (CNJC) is a singleloop Westinghouse PWR operated by Unión Fenosa Generación (UFG) and located in Almonacid de Zorita (Guadalajara), Spain (Fig. 1). José Cabrera is the oldest NPP in Spain. It initially went into commercial operation in 1969 and is rated at 160 megawatts-electric. It has had a number of safety upgrades installed since its initial construction. This has resulted in several backfits to the control room over the years. A Detailed Control Room Design Review (DCRDR) was conducted in the early 1990's using the methodology presented in NUREG-0700 [2]. Other control room reviews followed. A number of HEDs were identified and resolved. At the beginning of this study, several HEDs associated with MCR panel design remained to be addressed. The regulatory authority of Spain, the CSN, was concerned about extending the operating license of the facility with these discrepancies still outstanding.

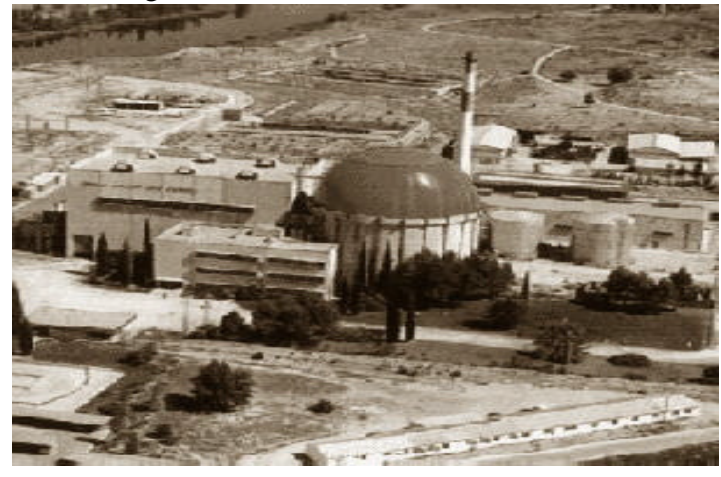

Fig. 1 Jose Cabrera Nuclear Power Plant 
The most significant discrepancy was the arrangement of the panels in two rows, with a front panel that impeded the direct access to specific safeguard controls, located in the back panel (see Fig. 2). These back panels had been added as part of plant upgrades after the initial design and construction of the plant. Displays and ontrols for use by operators in carrying out the plant's EOPs were distributed on front and back panels. This configuration contributed to risk in specific sequences of the PSA where important operator actions are required, such as in the switchover from the injection phase of Safety Injection (SI) to cold-leg recirculation during all loss-ofcoolant accidents (Locus). A number of possible improvements had been proposed (by various entities) up to and including a completely new control room. The key question at hand was: "How much upgrade is really needed in order to satisfactorily address the safety concerns?" the safety significance of the existing design and to better identify the human performance issues that needed to be addressed.

\section{IMPROVEMENTS TO THE CNJC CONTROL ROOM}

\section{A. Purpose of BNL Review}

The objective of the BNL review was to identify the potential impact on plant safety of the arrangement of the main control room (MCR) panels in two rows. If the impact turned out to be significant, then alternatives to reduce the risk associated with panel layout were to be identified for implementation.

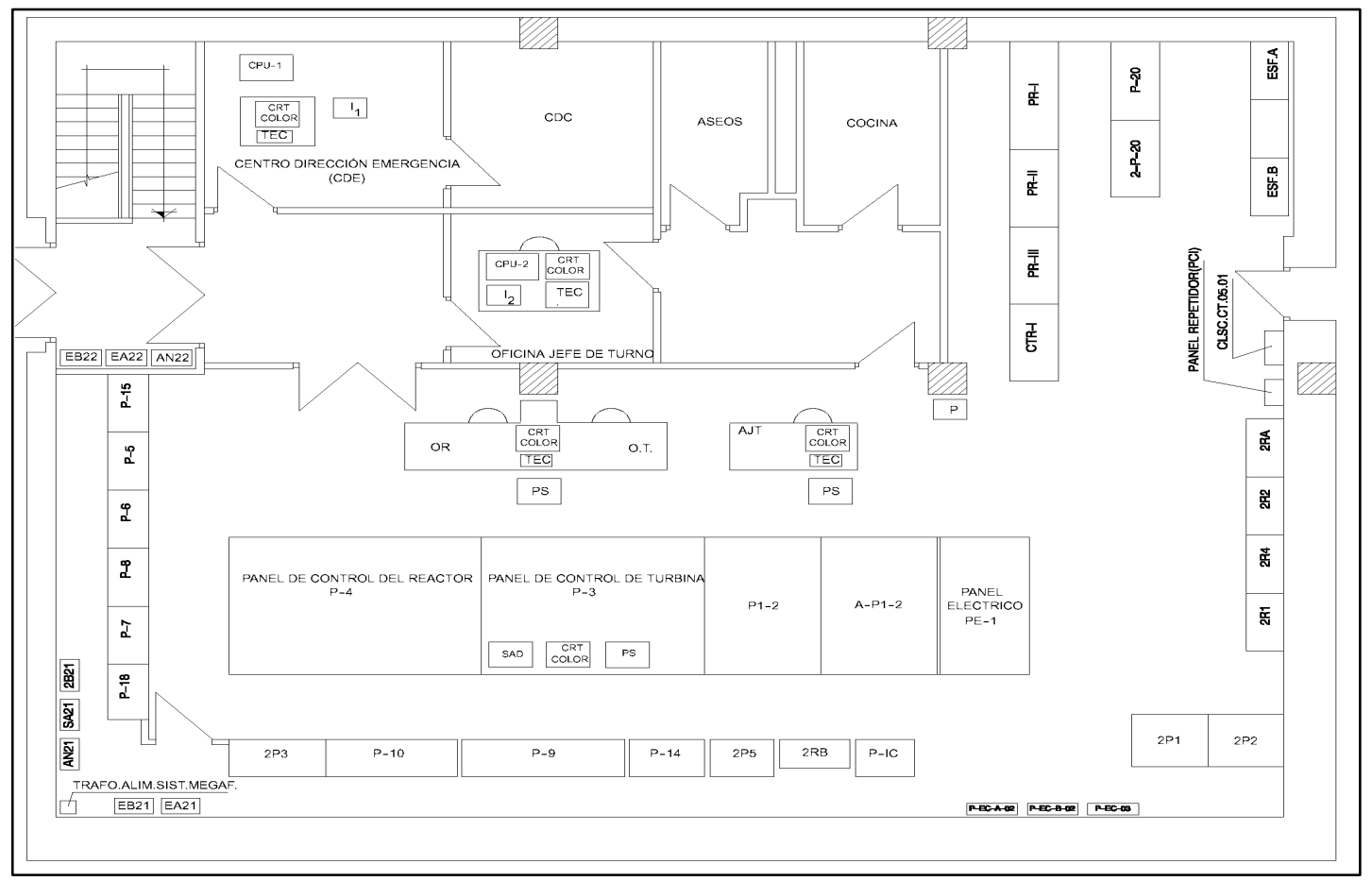

Fig. 2 CNJC control room layout

As a result of the identified issues with the MCR design, an independent international team of experts was established to review and evaluate the MCR. This team was led by Brookhaven National Laboratory and also had experts from Enconet of Vienna. Union Fenosa, Soluziona Ingeneria, and CNJC itself participated and played a key role, as the designers and operators of the plant. This study [3] was undertaken to evaluate the impact of the control room design on crew performance and plant safety. A program plan [4] to guide the study was prepared at the beginning of the project. The plan identified evaluations and analyses to be performed to confirm

\section{B. Methodology}

The principal technical basis for the evaluation methodology was the Human Factors Engineering Program Review Model of NUREG-0711 [1], and related references. These documents provide a strong, internationally accepted technical basis for human factors engineering (HFE). Our methodology was developed based on NUREG-0711, tailored as necessary to adapt it to this project, and was documented in a Program Plan [4].

The methodology consisted of five main steps: a description of current operations and the MCR, an analysis of 
the effects of the MCR configuration on crew performance, an identification and evaluation of alternative design configurations, a design for the selected alternative, and a verification $\&$ validation of the installed modification.

The description developed for the MCR was comprehensive and included: crew composition; operational practices; MCR layout (particularly the manner in which instrumentation was divided between the front and back panels); specific MCR controls, displays \& alarms; functional grouping of instrumentation; quality of HSI; operator aids, identifications of functions of front and back panels in emergency situations, and already planned upgrades.

The other aspects of the methodology are described in more detail below.

\section{An analysis of the effects of MCR configuration on crew performance}

Since the impact on safety of the panel arrangement is due to its effects on crew performance, the potential mechanisms by which such a configuration could impact crew performance and, therefore, risk were identified. Potential effects were identified in five areas: time delay, task performance, movement conflict, communication, and performance verification. Then three broad types of evaluations were performed to determine whether there was any evidence to support the existence of each these mechanisms or effects. The three types of evaluations performed were: risk evaluations, operating experience reviews, and task analyses.

1) Evaluation of Plant Risk and Vulnerabilities: This evaluation was performed to ensure that the items selected for modification are in fact risk significant and that they are the optimum items to modify in order to reduce plant and public risk. Preliminary information was that the dominant risk impact of the MCR panel arrangement was due failure of switchover to recirculation mode of SI. This post-accident switchover task requires operator actions at both the front and back panels. This risk evaluation was also used to assist the team in the selection of scenarios for the task analysis.

The risk analysis confirmed that the dominant contributor to the risk of core damage was failure of operators to properly realign SI for cold leg recirculation in several initiating events of the PSA. Important sequences noted were: LOCAs, SGTR, LOOP. Other important operator actions were: failures associated with SI in SGTR sequences, feed and bleed, and use of the secondary steam dump valves. The below graph (Fig. 3) illustrates the significant affect on core damage frequency (CDF) of changes in the quality of the HSI (and HEP) used during recirculation switchover. The plant condition at the beginning of the study is shown as poor on the x-axis. The final condition after all proposed modifications would be rated as good. The graphs show a full range of HEPs from 0 (perfect) to 1.0 (guaranteed failure).

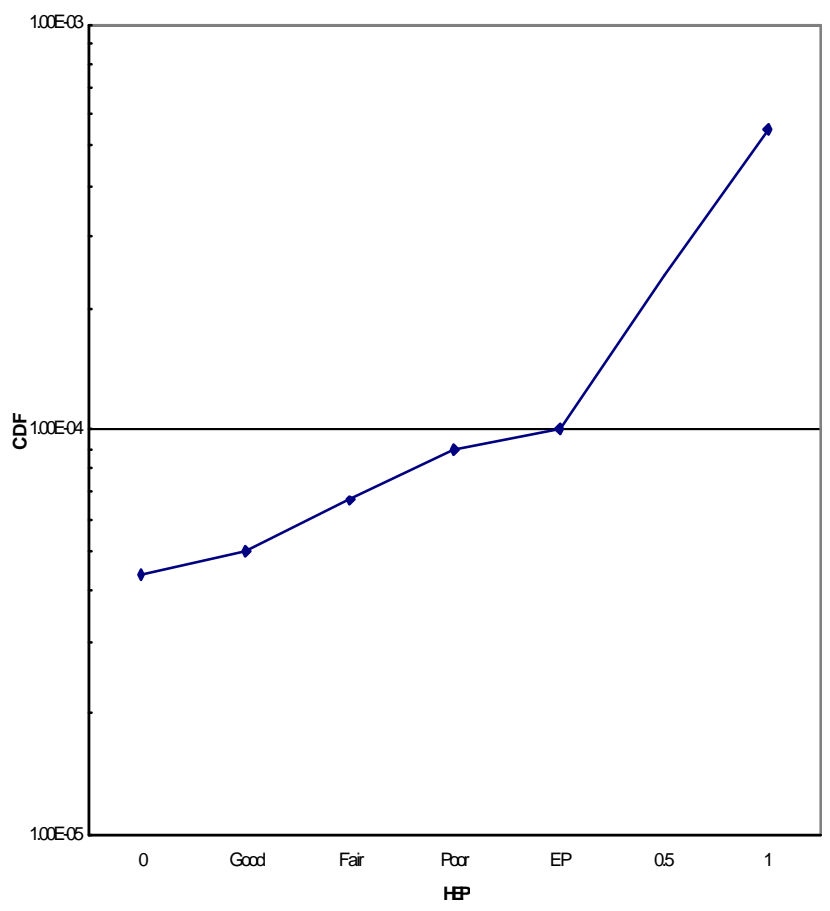

Fig. 3 Effect of HSI Quality on CDF Estimated

The related EOP evaluations revealed that significant back panel actions take place in all EOPs. Thus, the arrangement of EOP-related HSIs into front and back panels may have a significant impact on risk as defined in the five potential effects identified above.

2) Operating Experience Reviews (OERs): These OERs were detailed and diverse. They included the following four sources of information.

- Plant event reports and event report summaries.

- Summaries of operator interviews conducted as part of earlier studies by UF.

- A new OER report prepared by UF using the topical organization of NUREG-0711, Appendix B.

- New interviews with three crews of operators by the team.

The OER indicated that the overall operating experience and operator performance at Jose Cabrera has been reasonably good over the last ten years. Additionally, the operators that were interviewed appeared to be well-trained and knowledgeable. The operators felt comfortable with the control room and 
panel arrangement as they are currently configured. Nonetheless, some items related to back-panel operations, switchover to cold leg recirculation, and risk reduction were identified by the project team for possible implementation, as a result of the OER.

3) Task Analysis: Three scenarios were selected for examination based on: : (1) risk importance per PSA levels 1 and 2, including CDF contribution of initiating events, sequences, and top minimal cutsets; (2) information from our review of back panel operations in EOPs; and (3) operator interviews on actions in various scenarios. The three scenarios selected were: an intermediate LOCA requiring switchover to cold leg recirculation, a SGTR, and a LOOP. Task analyses of the scenarios were performed to provide detailed descriptions of what the personnel must do and the factors that could plausibly impact their successful completion.

Rather than doing task analyses using static procedures, we simulated the selected scenarios in the MCR in order to evaluate dynamic task performance. Note that Jose Cabrera did not have a plant specific training simulator with which the effects of the MCR layout on performance could be assessed. One scenario was walked through with full knowledge of the crew using EOPs and time lines. The other two were provided as drills with the shift supervisor and crew unaware of what accident they were to receive. The operators had to move through the control room and access panels and instruments in dynamic fashion based on the unfolding events. Conducting the simulations in this way made it possible to examine many aspects of the crew's performance in realistic fashion.

The evaluation of performance in the LOCA, SGTR, and LOOP scenarios was organized around the following factors:

- Procedure Sequences and Transitions

- Task Time

- Panel Operations

- Motion Conflicts

- Communication

- Verification of Crew Actions

- General Assessment

The results for each area of were based on a review of the EOPs, videotapes, and written transcripts for each scenario.

4) Overall conclusions on the effects of MCR configuration on crew performance: Overall performance of CNJC crews was good and the knowledge and skill of the crewmembers was high. However, it is important to ensure that the MCR design supports performance in situations where real-world stress and complications can occur. Thus, we summarize conclusions related to the five potential effects where the MCR configuration could impact crew performance.

Issue 1 - Time Delay Effect - The MCR configuration can add time to operator task performance because operators must navigate between front and back panels. This increased time can potentially lead to errors of omission (important actions are not performed on time) or significant delays in task performance, thereby eliminating margins necessary to deal with unforeseen complications and difficulties.

Conclusion - Little evidence for this concern was found, although as discussed above, there was one action whose actual time was much closer to thermal-hydraulic available time than most others. While the panel configuration increases task time, it is not significant enough to impact available time margins. A few minor areas for improvement were noted.

Issue 2 - Task Performance Effect - The configuration can impair individual task performance if the displays and controls for specific task performance are spread across individual panels. Such a design can increase operator error because it will lower the operator's situation awareness and increase their response implementation workload.

Conclusion - Some evidence for this concern was found. Additionally, some issues with the design of individual panels were identified.

Issue 3 - Movement Conflict Effect - The configuration can lead to conflicts in operators getting to the necessary panels or in reading indicators or operating controls. This affects operator task time and plant risk through the mechanisms described above.

Conclusion - No real evidence for this concern was found.

Issue 4 - Communication Effect - The configuration can make communication difficult and thus increase communication errors due to misunderstanding and difficulty hearing each other.

Conclusion - Some evidence for this concern was found.

Issue 5 - Performance Verification Effect - The configuration can impair the supervisor's ability to be aware of the actions of the RO and TO, to verify their task performance, and to identify and correct errors.

Conclusion - Evidence for this concern was found.

These findings lead to the following goals for the improvement of the MCR operation: 
- Increase, where possible, the time available to perform important operator actions.

- Reduce the number of transitions between panels, especially those of very short duration. This will not only reduce overall time, but will improve the situation awareness of operators and will minimize errors associated with task disruptions.

- Implement some general HFE improvements in the design of individual panels to minimize the potential for error.

- Improve communication between operators and the supervisor.

- Improve the ability of the supervisor to verify crew performance.

D. Design for the selected alternative: A broad array of methods and techniques were identified as potential means by which control room improvements could be made. Following the systems approach provided in the NUREG-0711 methodology, options were identified that extend well beyond control room hardware modifications to include aspects of training, procedures, staffing, and operations. The project team then assembled the options into six design alternatives. Each was a collection of options that together provided a complete approach to addressing the safety issues. The six alternatives were evaluated using human factors aspects, risk improvement, and cost, and then the optimum one was selected.

A brief summary of the modifications associated with the selected alternative follows. It primarily seeks to improve back panel operations for the RO by duplicating some of the front panel EOP-related displays and controls onto the back panel used for safety injection (P-9). Thus, the RO will not have to come to the front panel as frequently during EOP operations and can remain positioned at P-9. P-9 would also be improved by addressing outstanding discrepancies and adding human factors improvements, such as system demarcations and mimics. In addition, the alternative includes changes in organizational and administrative practices regarding: shift supervision, back panel operation, documentation, EOPs, training, and risk modeling. The alternative also includes SPDS improvements (such as, new screen displays for system flow diagrams and back panel equipment status monitoring). It also includes improvement of existing human factors conditions (MCR audio/video communications, back panel lighting; and new field labeling of risk-important local valves ).
A conceptual design was developed for all aspects of the selected alternative and submitted to the regulatory body (the CSN), who reviewed and approved the recommendations. Next a detailed design was completed and the modifications scheduled for implementation over a two outage cycle.

\section{E. Verification and Validation $(V \& V)$}

A preliminary V\&V plan, based primarily on NUREG-0711 was developed during the project and was later amplified by UF to ensure that the new HSI supports safe, efficient, and reliable personnel task performance. Additionally, some project team members visited the plant subsequent to installation of the upgrades to ensure that the design intent had in fact been met.

\section{CONCLUSIONS}

The recommendations of this study were the result of a systematic and multi-disciplinary analysis that was conducted independently from earlier studies. For each one of the alternatives presented, the following was completed:

- The human factors impact was reviewed.

- The risk impact and potential risk reduction were evaluated.

- The economic and time impact issues were considered.

The selected alternative addressed the human factors issues identified in the task analyses and reduced the risk due to CDF by about 30 to 50 percent. When economics are factored in, it was the best choice from a combined cost-benefit perspective. It provided for a notably upgraded CR without the major changes that had been previously suggested.

\section{ACKNOWLEDGMENT}

The authors gratefully acknowledge the contributions of Bojan Tomic and Mladen Susnic of Enconet; Aquilino Rodriquez, Julio E. Blanco, Juan M. Lupianez, Carlos Pomar, Jose L. Sastre and Emilio Rodriguez of Union Fenosa Generacion; and Pedro Ortega, and David Cano of Soluziona Ingenieria for their work on the project. We also recognize the valuable comments and interest of Jose I. Villadoniga and Benito Gil of the CSN. Finally, we acknowledge the professionalism and the cooperation of the operators at CNJC without whose assistance this project could not have been successful. 


\section{REFERENCES}

Technical Reports:

[1] O'Hara, J., Higgins, J., Stubler, W., Goodman, C., Eckenrode, R., Bongarra, J., and Galletti, G. (1994). Human Factors Engineering Program Review Model (NUREG-0711). Washington, D.C.: U.S. Nuclear Regulatory Commission

[2] O’Hara, J., Brown, W., Stubler, W., Wachtel. J., and Persensky, J. (1996). Human-system interface design review guideline (NUREG0700, Rev. 1). Washington, D.C.: U.S. Nuclear Regulatory Commission.

[3] John O'Hara, and James Higgins, Brookhaven National Laboratory, Bojan Tomic and Mladen Susnic, ENCONET Consulting, Aquilino Rodríguez, Julio Blanco, Juan M. Lupianez, Carlos Pomar, Jose L. Sastre and Emilio Rodriguez, Union Fenosa Generacion, Pedro Ortega, Pilar Almeida and David Cano, Soluziona Ingenieria, Risk Implications of the Panel Arrangement in the José Cabrera Nuclear Power Plant Control Room: Recommendations for Improvements, 31 January, 2001

[4] Program Plan, Risk Implications of the Present Panel Arrangement in the José Cabrera Nuclear Power Plant Control Room, BNL, Enconet, Union Fenosa Generacion, 22 November 2000

\section{BIOGRAPHIES}

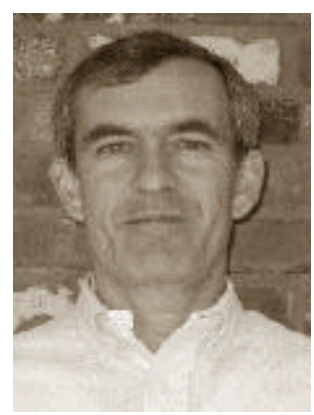

James C. Higgins (M'1978, SM'1994) was born in Philadelphia, Pa, USA on August 21, 1947. He graduated from the United States Naval Academy and the US Naval Postgraduate School.

His employment experience included the U. S. Navy on nuclear submarines, the U. S. Nuclear Regulatory Commission, and Brookhaven National Laboratory.

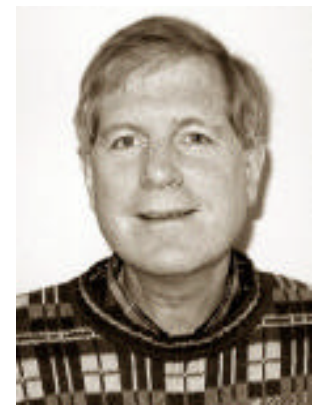

Dr. John O'Hara is a Scientist at Brookhaven National Laboratory and is the Human Factors Research Manager. His work is in the area of human-systems integration and address the effects of technology on crew performance and safety in complex systems. This research has led to the development of design and evaluation guidance for the human factors aspects of nuclear power plants. The guidance is used in many different countries and by many industrials outside

the commercial nuclear industry.

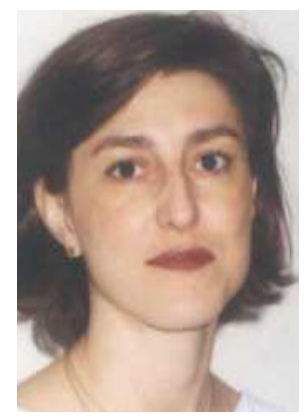

Pilar Almeida was born in Salamanca, Spain, on August 31, 1970. She graduated in Electronics at the University of Salamanca, and obtained a MSc degree in Nuclear Engineering, in 1994, organized by the CIEMAT (Madrid, Spain) and the Universidad Autonoma of Madrid, Spain. She works for SOLUZIONA Engineering, (Professional Services Company of the utility UNION FENOSA) since 1995. Currently, she is in charge of organizational and human factors issues of Jose Cabrera Nuclear Power Plant, and has worked in other nuclear fields: thermal hydraulic simulation, accident analysis, and severe accident management program for the Jose Cabrera NPP. 
